\title{
UNDERGRADUATE EDUCATION IN NUCLEAR ENGINEERING IN THE USA
}

\author{
W. R. MARTIN \\ Department of Nuclear Engineering, University of Michigan, Ann Arbor, MI 48109-2104 (USA)
}

(Received November 9, 1992)

\begin{abstract}
The discipline of nuclear engineering is described, giving some historical background to explain the structure of the curricula commonly found in nuclear engineering programs in the U.S. Typical curricula are described, along with a specific example given by the University of Michigan undergraduate program in nuclear engineering. The National Academy of Sciences report on U.S. nuclear engineering education is summarized, and the major findings are presented, including data on the number of programs, number of degrees, and enrollment trends. Some discussion is made of manpower trends and the degree to which nuclear programs can supply nuclear engineers to meet the anticipated demands of the current decade and into the next century.
\end{abstract}

The discipline of nuclear engineering has its origins in the World War II Manhattan Project. One of the more important milestones of this historic project was the successful fission chain reaction demonstrated by FERMI and colleagues at the University of Chicago in 1942. Although the field that we know now as nuclear engineering was not named at the time, the effort that went into the design and construction of FERMI's reactor exemplified the intrinsic interdisciplinary nature of this field, consisting as it did of an interplay between basic science and mathematics and fundamental engineering topics. Indeed, many aspects of the methodology that FERMI and colleagues developed for designing and analyzing this first nuclear reactor are still present in modem methods for reactor design and analysis. The contributions of eminent physicists, mathematicians, chemists, and engineers to the then-nascent field of nuclear engineering was essential to the subsequent development of nuclear engineering as a separate engineering discipline.

The need for nuclear engineers was first manifested in a demand for research-level scientists who would be involved in the early research and development activities in this field, primarily at the various national laboratories in both the weapons and nuclear submarine programs, although many were also needed to staff newly created academic programs in nuclear engineering. Many of these programs began in the early to late 1950 's, and were at first focused on graduate education since there was no demand for BS-level engineers at that time. The companies who participated in the development of light water reactors for the nuclear submarine program then began to commercialize their technology and this increased the demand for nuclear engineers in the civilian 
sector. The subsequent maturation of the commercial nuclear power industry created a demand for entry-level engineers in nuclear engineering, primarily to work for the many nuclear utilities who were in the process of purchasing, building, and operating nuclear power plants. To meet the resultant demand for engineers with the specialized background in reactor physics and reactor engineering, undergraduate curricula were established in the mid-1960's and later to provide BS-level engineers with formal training and education in nuclear engineering.

Today's nuclear engineers are involved in activities which were not even imagined during these formative years, such as nuclear fusion, medical applications, health physics, and the use of accelerators for basic materials studies and modification. These related activities are also characterized by a strong interdisciplinary nature, and evolution of nuclear engineering curricula has tended to emphasize basic physics and mathematics along with fundamental engineering subjects, to a degree greater than in most other engineering disciplines.

The following sections will describe in some detail the nuclear engineering curriculum that is commonly followed in most undergraduate programs in the U.S. which offer a degree in nuclear engineering, independent of whether the program is administered by a separate department or as a program within a larger department. To give some specific numbers, this discussion will be illustrated by the curriculum in nuclear engineering offered at the Univesity of Michigan, followed by statistics on the number of departments and programs, enrollments, and number of degrees granted. Employment pattems will be discussed, since they to a large extent shape the curriculum and provide the anticipated demand for nuclear engineers in the coming decade and next century. Much of this discussion is based on the recent report ${ }^{1}$ of the National Academy of Sciences (NAS), entitled U.S. Nuclear Engineering Education: Status and Prospects. The paper will conclude with some thoughts on the prospects for nuclear engineering education in the 21 st century, drawing heavily on the conclusions of the NAS Report ${ }^{1}$ as well as other sources cited in the references.

\section{Nuclear Engineering Curricula in the U.S.}

Undergraduate curricula in nuclear engineering evolved after graduate programs were already in place, and to varying extents the curricula reflect the desire to prepare students for graduate school. Given that nearly one quarter (perhaps one half at the University of Michigan) of the graduating BS students elect to go on to graduate school, this emphasis may be justified. This emphasis tends to increase the number of fundamental courses in mathematics and basic and applied sciences that are required of the undergraduate students. The next sections present some data on the typical nuclear 
engineering curriculum, much of which is taken from the NAS Report, which should be referenced for further detail and substantiation.

Most of the U.S. undergraduate programs in nuclear engineering require in the range of 130 to 135 semester hours ( $\sim 200$ quarter hours) and typically the first two years consist of fundamental courses in mathematics and science, including introductory physics, chemistry, and mathematics, as well as humanities courses and English and composition. The last two years include courses relevant to nuclear engineering, including reactor physics, reactor engineering and design, thermal-hydraulics, radiation

Table 1

Course requirements in nuclear engineering curricula in the U.S.A. ${ }^{a}$

\begin{tabular}{|c|c|c|c|c|}
\hline \multirow{2}{*}{ Curriculum area } & \multicolumn{4}{|c|}{ Required semester hours } \\
\hline & Minimum & Average & Maximum & $\mathrm{UM}^{\mathrm{b}}$ \\
\hline Calculus & 8 & 12 & 20 & 12 \\
\hline Differential equations & 3 & 4 & 6 & 4 \\
\hline Advanced mathematics & 2 & 3 & 15 & 11 \\
\hline Introductory physics & 6 & 9 & 15 & 11 \\
\hline Atomic and nuclear physics & 0 & 3 & 6 & 3 \\
\hline Chemistry & 3 & 9 & 14 & 5 \\
\hline Other basic science and mathematics & 1 & 3 & 6 & 0 \\
\hline Computing & 2 & 3 & - & 3 \\
\hline Numerical methods & 3 & 5 & 9 & 0 \\
\hline Statics & 1 & 3 & 6 & 2 \\
\hline Dynamics & 1 & 3 & 6 & 3 \\
\hline Fluid mechanics & 2.5 & 3 & 8 & 3 \\
\hline Materials & 0 & 3 & 6 & $\mathbf{0}$ \\
\hline Material science & 2 & 4 & 13 & 3 \\
\hline Electrical circuits & 3 & 3.5 & 9 & 3 \\
\hline Electronics & $\mathbf{0}$ & 3 & 6 & 1 \\
\hline Thermodynamics & 3 & 4 & 8 & 4 \\
\hline Heat transfer & 0 & 3 & 6 & 0 \\
\hline Nuclear physics & 2 & 5 & 7 & 3 \\
\hline Reactor physics & 3 & 5 & 8 & 7 \\
\hline Fusion & 0 & 3 & 4 & 0 \\
\hline Radiation defection & 0 & 2.5 & 5 & 4 \\
\hline Radiation effects & $\mathbf{0}$ & 2.5 & 3 & 0 \\
\hline Health physics & $\mathbf{0}$ & 2.5 & 4 & 0 \\
\hline System dynamics & o & 3 & 7 & 0 \\
\hline Thermal hydraulics & 0 & 3 & 7 & 0 \\
\hline Reactor engineering & 3 & 5 & 10 & 9 \\
\hline
\end{tabular}

\footnotetext{
a Based on Table F-21 in Reference 1.

${ }^{b}$ The UM values represent only required courses. The nuclear engineering electives have been added to "Reactor engineering", althogh the student may elect courses in fusion or boiling heat transfer, for example
} 
effects, and systems design. Some of the larger programs are able to offer more specialized courses such as radiation measurements, reactor safety, fusion technology, and medical applications. Table 1 indicates the range of semester hours for the major course areas in typical nuclear engineering curricula, while Table 2 compares the distribution of required courses in the basic science and engineering science areas for nuclear engineering versus other engineering disciplines. Portions of Tables 1 and 2 are based on Tables F-21 and F-22 in the NAS Report, respectively, with additional entries to illustrate the specific program at the University of Michigan (UM). While detailed data is not available for other institutions, at the UM the nuclear engineering curriculum requires substantially more mathematics than the other UM engineering programs, evidence of the emphasis in the nuclear engineering curriculum on fundamental mathematics, basic science, and engineering science. Table 3 summarizes the detailed curriculum in nuclear engineering at the University of Michigan. It should be noted that Tables 1 and 2 represent only required courses, meaning that they are minimum course

Table 2

Average semester hour requirements vs. engineering discipline ${ }^{a}$

\begin{tabular}{lrrrrrrrrr}
\hline \multicolumn{1}{c}{ Curriculum area } & \multicolumn{7}{c}{ Engineering discipline } \\
\cline { 2 - 8 } & Mech $^{\mathrm{b}}$ & Elec & Civil & Ind & Aero & Matls & Nucl & UM $^{\mathrm{c}}$ \\
\hline Physics & 10 & 12 & 10 & 9 & 7 & 10 & 22 & 17 \\
Chemistry & 6 & 8 & 7 & 6 & 7 & 11 & 7 & 5 \\
Mechanics & 12 & 3 & 9 & 5 & 11 & 5 & 7 & 5 \\
Thermal science & 12 & 2 & 2 & 2 & 6 & 5 & 9 & 4 \\
Electrical/electronics & 6 & 28 & 2 & 3 & 5 & 4 & 5 & 4 \\
Nuclear science & 0 & 3 & 0 & 0 & 0 & 3 & 6 & 11 \\
\hline
\end{tabular}

\footnotetext{
${ }^{a}$ Based on Table F-22 in Reference 1.

${ }^{b}$ Mech - Mechanical engineering, Elec - Electrical engineering, Ind - Industrial engineering, Aero - Aerospace engineering, Matls - Materials Engineering, Nucl - Nuclear engineering, UM - Nuclear en gineering (University of Michigan).

${ }^{c}$ The UM number represents the required semester hours in each of the curriculum areas. (Elective courses can add substantially to these numbers.)
}

lists which may differ considerably from the typical selection of courses a student may take after elective courses are taken. This is illustrated by the UM curriculum in Table 3, where 28 semester hours are elective, including 12 hours in nuclear engineering. This flexibility, which is not unique to the UM, gives the students the option to prepare for graduate school, or for employment following the BS degree, or to prepare for a specialty such as nuclear fusion, nuclear materials, radiation measurements, or health physics. 
Table 3

The University of Michigan, curriculum in nuclear engineering

\begin{tabular}{lc}
\hline \multicolumn{1}{c}{ Course area } & Semester hours \\
\hline Calculus (incl. differential equations) & 16 \\
English composition & 4 \\
Computing & 3 \\
Chemistry & 5 \\
Introductory physics & 8 \\
Technical communication & 3 \\
Humanities and social sciences & 17 \\
Advanced physics & 3 \\
Advanced calculus & 4 \\
Advanced mathematics & 3 \\
Materials & 3 \\
Statics & 2 \\
Solid mechanics & 3 \\
Thermodynamics & 4 \\
Circuit analysis/electronics & 4 \\
Fluid mechanics & 3 \\
Nuclear science & 6 \\
Nuclear instrumentation & 4 \\
Nuclear reactor analysis & 4 \\
Nuclear engineering electives & 9 \\
Technical electives & 9 \\
Free electives & 7 \\
Total hours: & 128 \\
\hline
\end{tabular}

Some departments offer options or concentrations at the undergraduate level, although in many cases these are informal options which the student can exercise via course elections. For example, at the UM, a student who would like to take additional courses in nuclear fusion would be urged to take undergraduate physics courses in dynamics and electromagnetic field theory before taking senior year nuclear engineering courses in controlled nuclear fusion and fusion technology. A student at the UM can also concentrate in the materials area by taking courses in materials science and metallurgy while taking his usual courses in nuclear engineering. These alternatives are not formal options, but are allowed by the flexible curriculum at the UM which allows the student a large number of electives in nuclear engineering as well as numerous technical electives and free electives. Table 4, which is taken from the NAS Report, presents some data on the number of areas of specialization offered by institutions which grant nuclear engineering degrees. Clearly there is substantial diversity in the areas of specialization, although as noted above, there appears to be some agreement with respect to the basic structure of nuclear engineering curricula across the country. 
Table 4

Numbers of institutions with given areas of strength ${ }^{a}$

\begin{tabular}{lc}
\hline \multicolumn{1}{c}{ Area } & $\begin{array}{c}\text { Number } \\
\text { of institutions }\end{array}$ \\
\hline Reactor engineering & 10 \\
Systems analysis and safety & 10 \\
Artificial intelligence & 2 \\
Advanced reactors & 5 \\
Radiation transport & 7 \\
Radiation effects & 6 \\
Nuclear materials & 4 \\
Radiation detection & 5 \\
Health physics & 5 \\
Criticality safety & 4 \\
Waste management & 7 \\
Fusion and plasma physics & 10 \\
Accelerators & 1 \\
\hline
\end{tabular}

abased on Table 4-5 in Reference 1.

\section{Status of Nuclear Engineering Departments in the U.S.}

This section will summarize the current status of nuclear engineering departments, including enrollments and number of degrees granted, and a discussion of the manpower demands for nuclear engineers into the next century. Much of this data is taken from the NAS Report, which will be briefly described in the next paragraph due to its significance to the field of nuclear engineering in the U.S.

The NAS Report. The NAS Report presents a particularly compelling case for the decline in nuclear engineering programs over the past decade or so, and a few of the more significant indicators are given below. This report was commissioned by the NAS because of a number of concerns, including the declining number of nuclear engineering programs, declining enrollments, the decrease in research funding (especially in fission reactor engineering), and the increasing number of graduate students from foreign countries. The major findings contained in the NAS Report were the following:

(1) nuclear engineering is a unique discipline, with specialized education and training that cannot be substituted for by other disciplines,

(2) from 1978 to 1988 , the following decreases in enrollments and other measures occurred:

- enrolles seniors: 1150 to 650 ,

- enrolled MS: 1050 to 600 , 
- university research reactors: 76 to 27 ,

- nuclear engineering programs: 80 to 57 ,

(3) the demand for electricity will continue to rise,

(4) the supply of nuclear engineers will not meet the demand, even if there are no new nuclear plants built,

(5) the nuclear engineering faculty are somewhat older (approximately ten years) than engineering faculty as a whole,

(6) to replace retiring faculty, about $15 \%$ of graduated $\mathrm{PhDs}$ over the next decade will be needed,

(7) research funding has shifted away from conventional fission reactor engineering, with very little basic research funded by the government in this area. With respect to the first finding, the NAS Report recognizes the unique nature of the nuclear engineering curriculum and the difficulty that graduates of other disciplines would have to fill typical nuclear engineering positions. The second finding summarizes the compelling evidence of the decline in nuclear engineering education over the past decade or so. This decline is problematical, however, due to finding (3), namely that electricity demand will continue to rise, which is why the supply of nuclear engineers will not meet the demand, as noted in finding (4), especially if there is an increase in

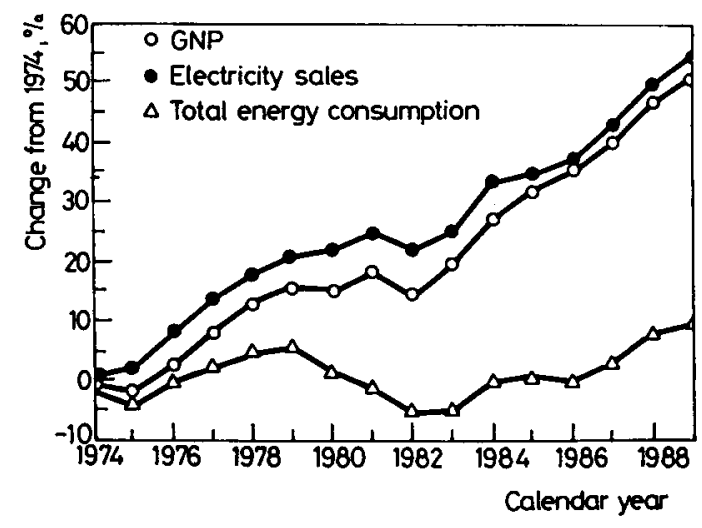

Fig. 1. Electricity sales and GNP, 1974-1989²

the number of nuclear power plants built in the U.S. over the next decade or in the next century. Figure 1 illustrates the historical connection between gross national product (GNP) and the demand for electricity, and it can be seen that this correlation has held true for nearly 20 years, and is expected to hold into the next century. Therefore, as concluded in the NAS Report, there is a reasonable chance that demand will outstrip 
supply, especially if the nuclear programs are allowed to continue their decline, which may happen due to findings (5) and (6), the relative aging of nuclear faculty and the fact that a substantial portion of graduating $\mathrm{PhDs}$ will be needed to replace retiring faculty over the next decade. Moreover, this situation is exacerbated by finding (7), the lack of sufficient research funding in conventional fission reactor areas, because it will be difficult to influence faculty to either enter to remain in this field. This last issue, research funding in nuclear engineering, is a separate and interesting (and contentious) issue, but is beyond the scope of this paper, and the interested reader should refer to the NAS Report or several other papers written in the past two years which address this topic as well as undergraduate nuclear engineering curricula in general..$^{3-9}$

Number of programs. The DOE conducts an annual survey of institutions with programs offering a major in nuclear engineering, or which offer nuclear engineering options in other departments. The Appendixes to the 1991 survey ${ }^{10}$ lists 28 academic institutions which offer undergraduate degrees in nuclear engineering as majors, and 41 institutions which offer undergraduate nuclear engineering options as part

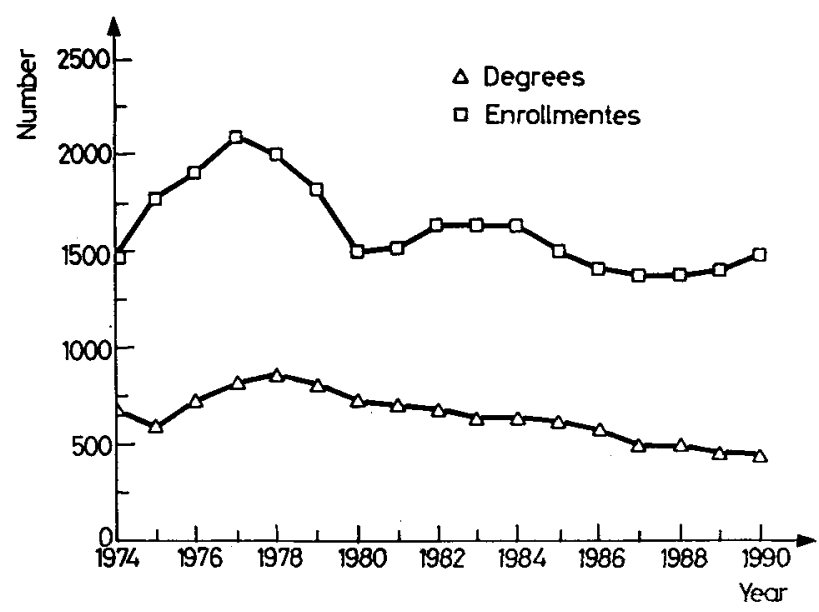

Fig. 2. Nuclear engineering undergraduate enrollments and degrees; ${ }^{12}$ Undergraduate - Junior and senior level. Source: U.S. Department of Energy.

of other degree programs, including chemical engineering ( 4 programs), engineering science (6), electrical engineering (7), mechanical engineering (13), nuclear chemistry (1), civil engineering (1), engineering management (1), engineering physics (2), marine engineering (2), materials engineering (1), nuclear science (1), and physics (2). (Some of the above institutions offer both a major in nuclear engineering as well as options in 
other programs.) Of the 28 programs which offer a degree in nuclear engineering, 24 are accredicted by the Accreditation Board for Engineering and Technology (ABET). ${ }^{11}$

Enrollment trends. Figure 2, taken from Reference 12, summarize the results of the survey pertinent to undergraduate nuclear engineering. Figure 2 includes part-time as well as students in option programs, and $61 \%$ of the number shown are actually enrolled as nuclear engineering majors. As can be seen, the number of degrees granted is showing a persistent decline, although the enrollment figures are showing a steady but small increase, probably due to the inclusion of part-time students in the data. With respect to all engineering programs, nuclear engineering represents less than $1 \%$ of the total BS enrollment in engineering.

Manpower trends. Reference 12 also discusses the employment and postgraduation plans of nuclear engineering graduates in 1990, and notes that $25 \%$ of the BS graduates continue to graduate school, with the largest fraction of the remaining graduates are hired by utilities. It appears that future graduates will not have difficulty finding jobs, however, since the NAS Report discusses the balance between supply and demand for nuclear engineers well into the next century, and it is shown that supply will not meet demand, even if no new nuclear plants are built. Here it should be noted that much of this demand is in the area of radioactive waste management and environmental remediation, which are expected to be growth fields throughout the 1990s.

\section{Summary and conclusions}

The discipline of nuclear engineering is a viable and well-defined field of study which provides uniquely trained engineers to work in engineering and scientific fields related to the use of nuclear energy and nuclear radiation for scientific and industrial applications. The curriculum reflects the broad and diverse nature of a nuclear engineer's responsibilities, characterized by an emphasis on fundamental science and engineering topics, and supplemented by specialized courses in specific nuclear the past 15 years, including enrollments, degrees granted, the number of nuclear engineering programs, and the aging of the nuclear engineering faculty. Given that the demand for nuclear engineers is expected to exceed supply over the next decade and into the next century, even if no new nuclear plants are built, this is a potentially serious problem tha needs to be addressed by industry, academe, and the government. 


\section{References}

1. National Academy of Sciences - National Research Council, U.S. Nuclear Engineering Education: Status and Prospects, National Academy Press, Washington,D.C., 1990.

2. C. K. EBINGER, J. P. BANKS, M. S. MORGAN, Nuclear Power: The Promise of New Technologies, Figure 3, The Center for Strategic and International Studies, Washington, D.C., 1991.

3. J. W. POSTON, The Changing Face of Nuclear Engineering Education, Trans. Am. Nucl. Soc., 63 (1991) 19.

4. W. R. MARTIN, National Research Council Report and Its Impact on Nuclear Engineering Education at the University of Michigan, Trans. Am. Nucl. Soc., 63 (1991) 19.

5. T. S. ELLEMAN, J. G. GILLIGAN, Environmental and Waste Disposal Options in Nuclear Engineering Curricula, Trans. Am. Nucl. Soc., 63 (1991) 20.

6. E. H. KLEVANS, Penn State's Nuclear Engineering Curriculum as it Relates to the National Academy Recommendations, Trans. Am. Nucl. Soc., 63 (1991) 21.

7. D. M. WOODALL, ABET and ANS Guidance for Nuclear Engineering Curricula and Programs, Proc. ASEE Annual Conf., 1480, Toledo, OH, 1992.

8. W. R. MARTIN, Nuclear Engineering at the University of Michigan, Proc. ASEE Annual Conf., 1482, Toledo, $\mathrm{OH}, 1992$.

9. D. MILLER, Undergraduate Nuclear Engineering at The Ohio State University, Proc. ASEE Annual Conf., 1485, Toledo, $\mathrm{OH}, 1992$.

10. U.S. Department of Energy, Nuclear Engineering Enrollments and Degrees, 1990, Appendixes, prepared by Labor and Policy Studies Program, Science/Engineering Education Division, Oak Ridge Associated Universities, Oak Ridge, TN, July 1991.

11. American Society for Engineering Education (ASEE), 1992 Directory of Undergraduate Programs in Engineering and Engineering Technology, Washington, D.C., 1992.

12. U.S. Department of Energy, Manpower Assessment Brief, Number 14, Office of Energy Research, University and Science Education Programs, July 1991. 